\title{
Effects of Sintering Temperature on Crystallinity, Morphology, and Photocatalytic Activity of $\mathrm{Bi}_{2} \mathrm{O}_{3}$
}

\author{
Mukholit, Heri Sutanto*, Ngurah Ayu Ketut Umiati, Eko Hidayanto \\ Department of Physics, Diponegoro University, Semarang Indonesia
}

\begin{abstract}
$\mathrm{Bi}_{2} \mathrm{O}_{3}$ has successfully been synthesized using precipitation method with sintering temperature variations of $400^{\circ} \mathrm{C}, 450^{\circ} \mathrm{C}, 500^{\circ} \mathrm{C}, 550^{\circ} \mathrm{C}$, and $600^{\circ} \mathrm{C}$. Crystallinity property of resulting $\mathrm{Bi}_{2} \mathrm{O}_{3}$ powder has also been tested with XRD and morphology properties were tested with SEM. Meanwhile, photocatalytic properties were tested by using it to degrade Rhodamine B under sunlight. Results of XRD tests show that differences in sintering temperature affect crystallite size. Increases in sintering temperature between $400^{\circ}$ $\mathrm{C}$ and $500^{\circ} \mathrm{C}$ result in greater crystallite size, whereas sintering temperature between $550^{\circ} \mathrm{C}$ and $600^{\circ} \mathrm{C}$ result in smaller crystallite size. Results of SEM tests show that resulting $\mathrm{Bi}_{2} \mathrm{O}_{3}$ has rod-like structure, While results of degradation tests show that increases in sintering temperature enhances photocatalytic activities of $\mathrm{Bi}_{2} \mathrm{O}_{3}$, as evident with $\mathrm{Bi}_{2} \mathrm{O}_{3}$ undergoing sintering at $600{ }^{\circ} \mathrm{C}$ was able to degrade Rhodamine $\mathrm{B}$ with $56.74 \%$ effectiveness and degradation rate of $0.007 \mathrm{ppm} / \mathrm{min}$.
\end{abstract}

Keywords: Bismuth Oxide, Photocatalytic, Microstructure, Degradation, Sintering

\section{Introduction}

Over the past few years, research on semiconductor-based photocatalysis has been gaining interest as it has wide-ranging applications, from gas sensor, electrochromic material, solar energy conversion, optoelectronic devices, to optical layers [1][2][3]. Traditional photocatalytic materials such as $\mathrm{TiO}_{2}, \mathrm{ZnO}$, and $\mathrm{BiPO}_{4}$ have incredible photocatalytic performance under ultraviolet light irradiation but their energy gaps are too wide to be able to absorb visible light [3][4][5]. This is quite a drawback as UV only makes up $5 \%$ of the total sunlight reaching the Earth [6][7].Therefore, researchers try to develop photocatalytic materials that can be activated by visible light such as $\mathrm{Bi}_{2} \mathrm{O}_{3}$ with an energy gap of $2.8 \mathrm{eV}[8][9][10]$.

$\mathrm{Bi}_{2} \mathrm{O}_{3}$ possesses advantageous characteristics such as significant photoluminescence, high reflective index (2.3), high photoconductivity, high thermal chemistry stability, low resistivity, being non-poisonous, and good photocatalytic activities [11][12][13]. $\mathrm{Bi}_{2} \mathrm{O}_{3}$ comes in six phases of: $\alpha$ - $\mathrm{Bi} 2 \mathrm{O} 3$ (monoclinic), $\beta-\mathrm{Bi}_{2} \mathrm{O}_{3}$ (tetragonal), $\gamma-\mathrm{Bi}_{2} \mathrm{O}_{3}$ (body-centered cubic), $\delta-\mathrm{Bi}_{2} \mathrm{O}_{3}$ (face-centered cubic), $\varepsilon-\mathrm{Bi}_{2} \mathrm{O}_{3}$ (orthorhombic), and $\omega$ $\mathrm{Bi}_{2} \mathrm{O}_{3}$ (triclinic) [14]. Out of those six phases, $\alpha-\mathrm{Bi}_{2} \mathrm{O}_{3}$ is the most stable, while $\beta-\mathrm{Bi}_{2} \mathrm{O}_{3}$ is slightly less stable than $\alpha-\mathrm{Bi}_{2} \mathrm{O}_{3}$. Meanwhile, $\gamma-\mathrm{Bi}_{2} \mathrm{O}_{3}, \delta-\mathrm{Bi}_{2} \mathrm{O}_{3}, \varepsilon-\mathrm{Bi}_{2} \mathrm{O}_{3} \omega-\mathrm{Bi}_{2} \mathrm{O}_{3}$ are metastable phases [15].

\section{Methodology}

$\mathrm{Bi}_{2} \mathrm{O}_{3}$ was synthesized using precipitation method as depicted in Figure 1. $\mathrm{Bi}\left(\mathrm{NO}_{3}\right)_{3} .5 \mathrm{H}_{2} \mathrm{O}$ was used as $\mathrm{Bi}$, $\mathrm{HNO}_{3}$ source that served as solvent, and $\mathrm{NaOH}$ served as the catalyst. First, $0.5 \mathrm{~g}$ of $\mathrm{Bi}\left(\mathrm{NO}_{3}\right)_{3} .5 \mathrm{H}_{2} \mathrm{O}$ was dissolved in $50 \mathrm{ml}$ of $5 \% \mathrm{HNO}_{3}$ solution. The process was performed by stirring both materials using a stirrer. Afterwards, $250 \mathrm{ml}$ of $\mathrm{NaOH}$ was added to the solution and was then further stirred using a stirrer for 2 hours in order to produce precipitate. Precipitate and solution were separated using filter paper before being heated to $120^{\circ} \mathrm{C}$ to evaporate the water and produce $\mathrm{Bi}_{2} \mathrm{O}_{3}$ powder. The $\mathrm{Bi}_{2} \mathrm{O}_{3}$ powder that no longer contain water was then undergoing sintering in a furnace at temperatures of $400^{\circ} \mathrm{C}, 450^{\circ} \mathrm{C}, 500^{\circ} \mathrm{C}, 550^{\circ} \mathrm{C}$, and $600^{\circ} \mathrm{C}$ for 4 hours, respectively. Resulting materials were then designated samples A, B, C, D, and E. The next step was characterization. Characterizations were performed using XRD to find out their crystallinity and SEM-EDX to figure out their morphology. 


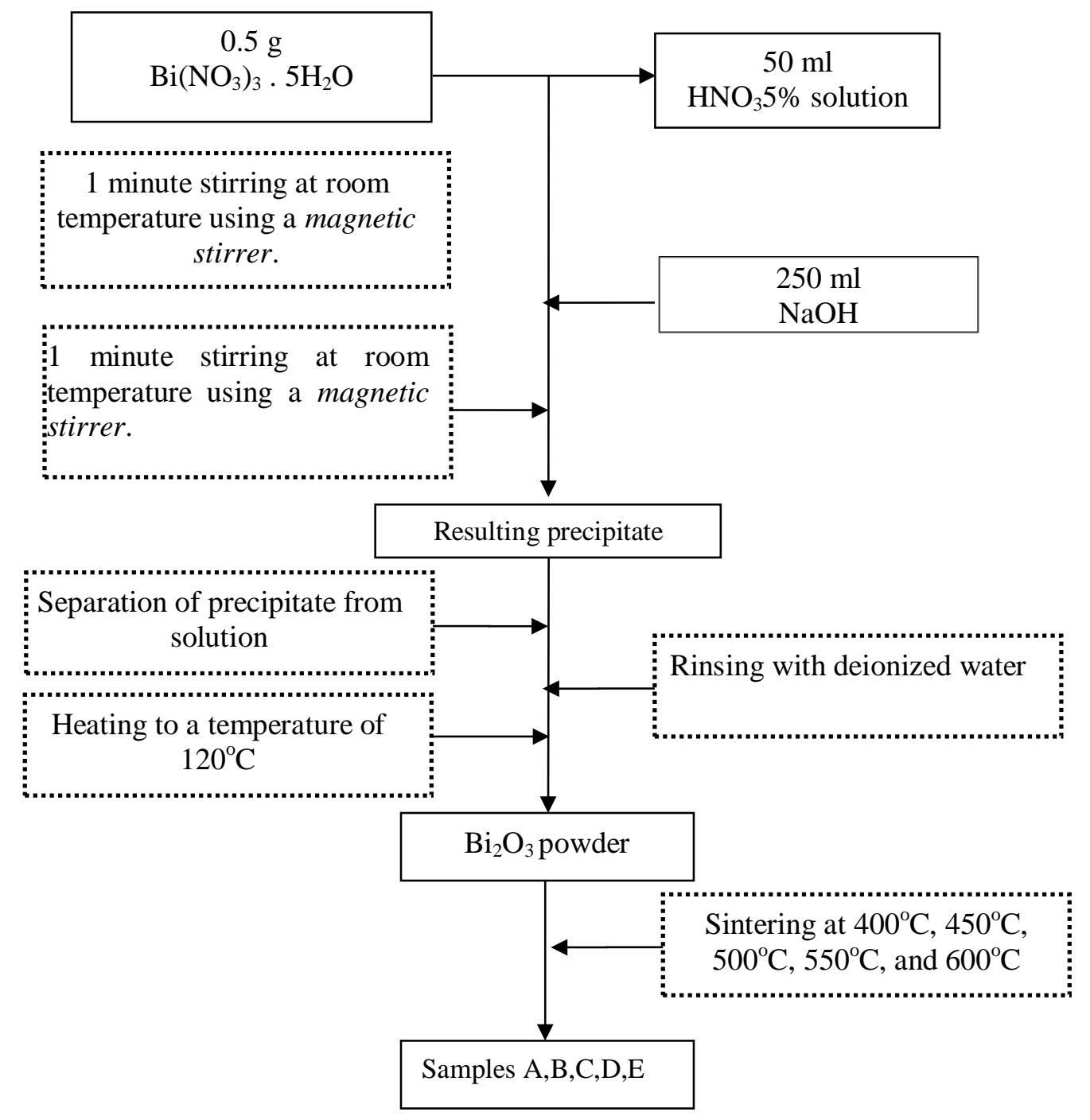

Figure $1 . \mathrm{Bi}_{2} \mathrm{O}_{3}$ synthesis using precipitation method

\section{Results and discussion \\ XRD Analysis}

Results of XRD analysis are depicted in Figure 2. Based on JCPDS, No. 27-0053, diffraction peaks are at $21.75^{\circ}, 25.76^{\circ}, 25.56^{\circ}, 26.91^{\circ}, 27.39^{\circ}, 28.01^{\circ}, 33.96^{\circ}, 35.04^{\circ}, 37.57^{\circ}, 46.29^{\circ}, 48.59^{\circ}, 52.09^{\circ}, 52.38^{\circ}, 52.98^{\circ}$, $54.80^{\circ}, 55.45^{\circ}, 55.88^{\circ}, 57.78^{\circ}, 58.29^{\circ}, 62.31^{\circ}, 63.55^{\circ}$, which show diffraction of $(020),(021),(002),(112)$, (121), (012), (202), (212), (113), (223), (104), (313), (322), (233), (241), (224), (323), (304), (143), (152), (213). In general, increasing sintering temperatures result in higher and sharper diffraction peaks. No diffraction peak was found in sample A. This means that sample A is amorphous. Sample B has three diffraction peaks. This means that $450^{\circ} \mathrm{C}$ is adequate to change amorphous structure into crystalline structure. Figure 2 also reveals that the number of diffraction peaks increases, as sintering temperature rises. This means that raising sintering temperatures speeds up transformation from amorphous $\mathrm{Bi}_{2} \mathrm{O}_{3}$ into crystalline $\mathrm{Bi}_{2} \mathrm{O}_{3}$. Higher sintering temperature results in better crystallite quality. This is supported by results from degradation test. Higher sintering temperature results in better degradation outcome. Higher crystallinity results in higher photocatalytic activities. Therefore, sample $\mathrm{A}$ is amorphous $\mathrm{Bi}_{2} \mathrm{O}_{3}$ with the lowest photocatalytic activity. In amorphous materials, electrons and holes play the role of easily recombined photocatalysis [16] Results from XRD test also reveal that crystallite size is affected by sintering temperature. Crystallite size is measured using the Scherrer formula (Equation 1) [17].

$$
\mathrm{Cs}=\frac{c \lambda}{F W H M(\cos \theta)}
$$


With Cs is crystallite size, $\mathrm{c}$ is a constant (shape factor), $\lambda$ is the $\mathrm{X}$-Ray wavelength, FWHM is the full width at half maximum of characteristic diffraction peaks. Calculation results using Equation 1 are shown in Table 1.

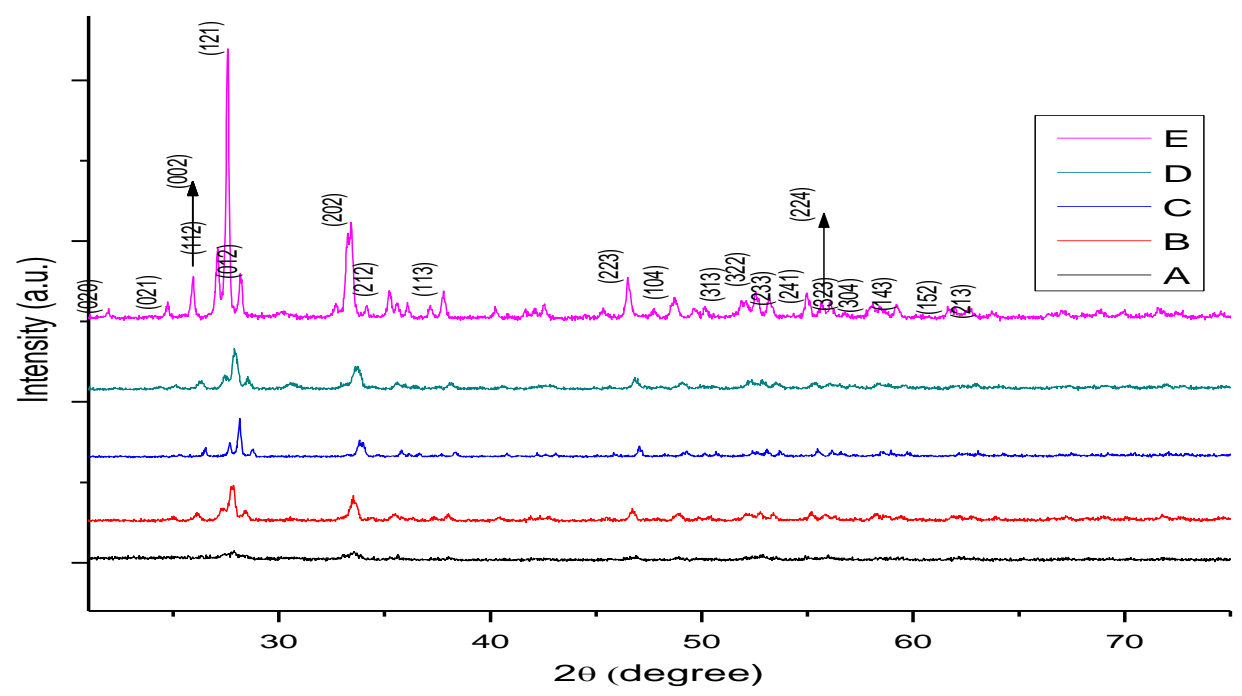

Figure 2. Results of XRD analysis

Table 1 Crystallite size

\begin{tabular}{|r|r|r|r|r|}
\hline Sample & FWHM (rad) & 2 theta (degree) & $\lambda(\mathrm{nm})$ & $D(\mathrm{~nm})$ \\
\hline A & - & - & - & - \\
\hline B & 0.322 & 27.573 & 0.154 & 25.437 \\
\hline C & 0.287 & 27.794 & 0.154 & 28.544 \\
\hline D & 0.159 & 27.927 & 0.154 & 51.458 \\
\hline E & 0.147 & 28.141 & 0.154 & 55.658 \\
\hline
\end{tabular}

It can be seen in Table 1 that FWHM decreases from sample A to sample E. This decrease in FWHM also confirms that crystallinity increases with rising sintering temperature. Table 1 also reveals that higher sintering temperature results in shifting diffraction peaks. Raising sintering temperature also affects crystallite size. Higher sintering temperature results in greater crystallite size.

\section{SEM-EDX analysis}

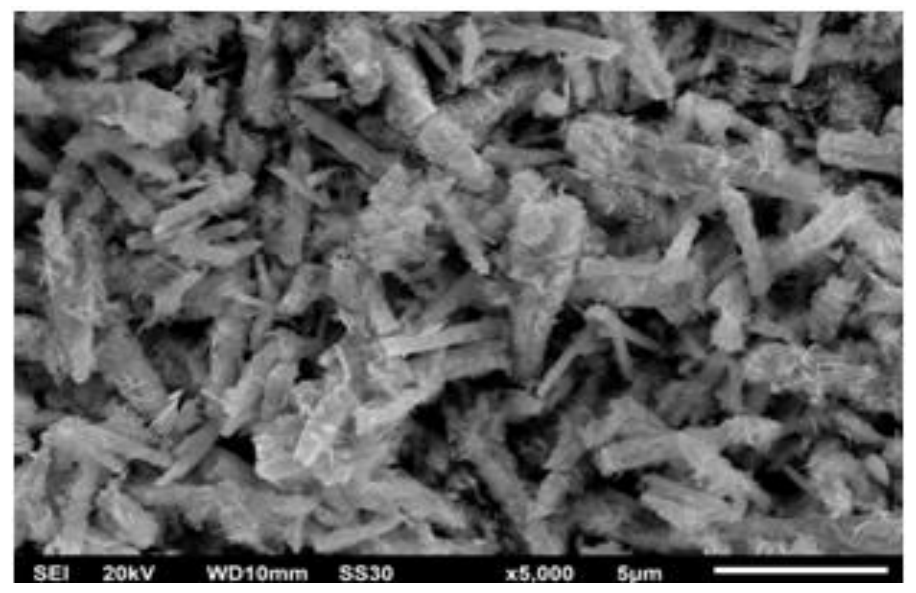

(A)

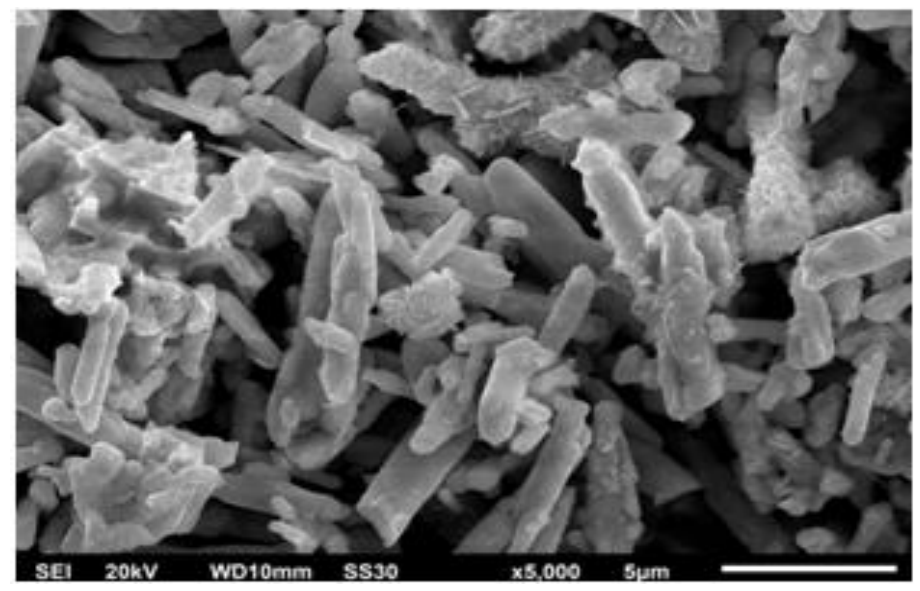

(B) 


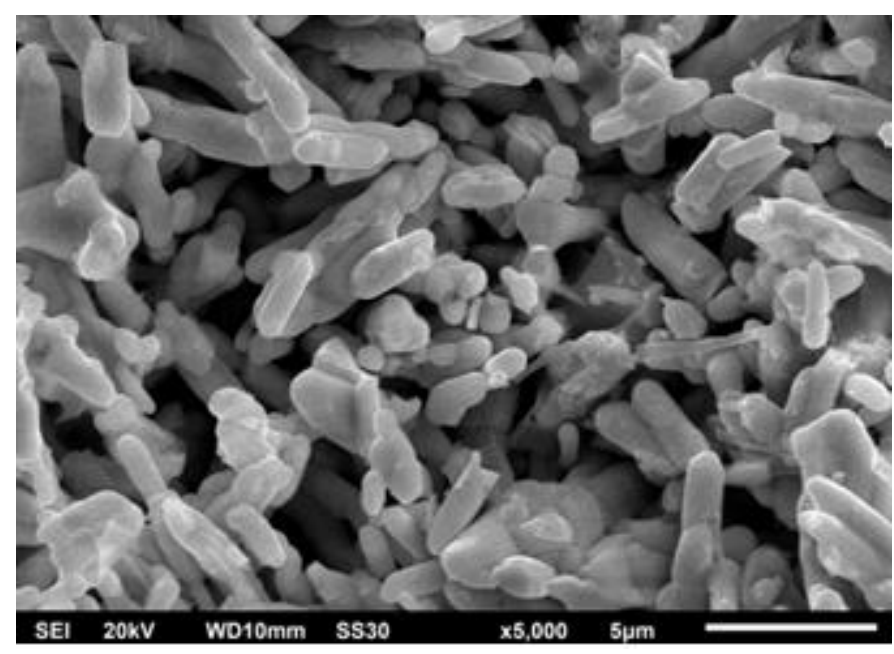

(C)

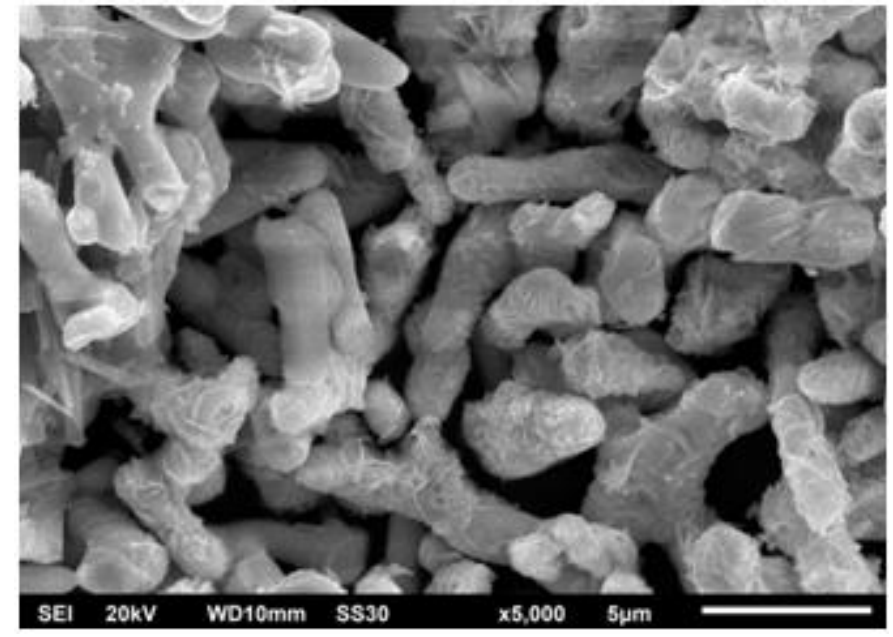

(D)

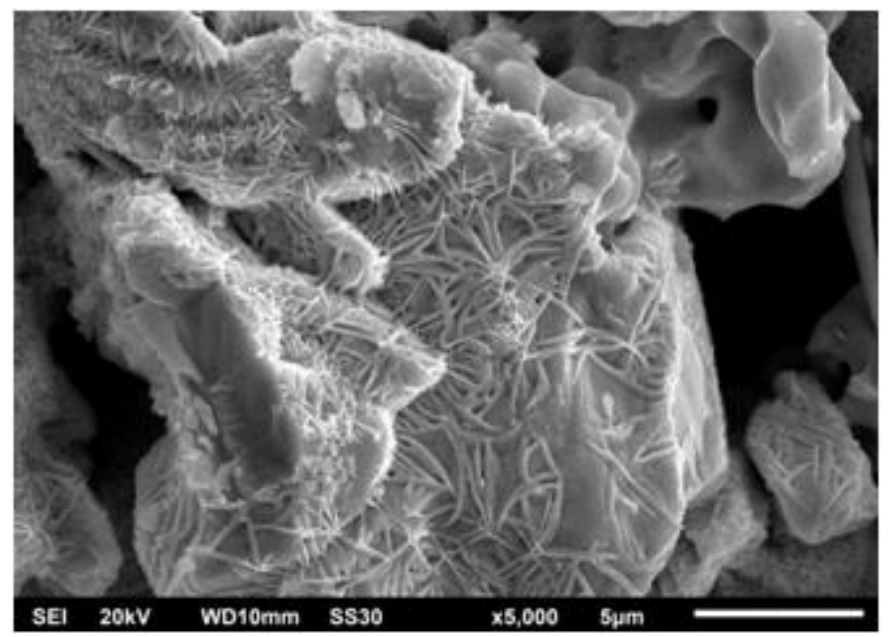

(E)

Figure 3. Results of SEM analysis

Results of SEM test show that sintering temperature affects $\mathrm{Bi}_{2} \mathrm{O}_{3}$ morphology. Figure 3. Shows that resulting $\mathrm{Bi}_{2} \mathrm{O}_{3}$ has rod-like structure. Sample A, which as sintered at $400^{\circ} \mathrm{C}$, appears to have rough rod structure. Raising sintering temperature from $400^{\circ} \mathrm{C}$ to $500^{\circ} \mathrm{C}$ caused alteration in $\mathrm{Bi}_{2} \mathrm{O}_{3}$ rod structure, from being rough to become smoother. When sintering temperature was raised to $550^{\circ} \mathrm{C}, \mathrm{Bi}_{2} \mathrm{O}_{3}$ particles started to experience agglomeration. Sintering at $600^{\circ} \mathrm{C}$ caused extensive agglomeration and the rod-like structure of $\mathrm{Bi}_{2} \mathrm{O}_{3}$ is no longer visible. SEM images also show that raising sintering temperature from $400^{\circ} \mathrm{C}$ to $500^{\circ} \mathrm{C}$ caused particle growth, whereas raising sintering temperature from $500^{\circ} \mathrm{C}$ to $600^{\circ} \mathrm{C}$ caused agglomeration. This means that the optimum temperature for particle growth is $500^{\circ} \mathrm{C}$.

\section{Degradation Test}

Photocatalytic activity of $\mathrm{Bi}_{2} \mathrm{O}_{3}$ was tested for its ability to degrade $10 \mathrm{PPM}$ of Rhodamine $\mathrm{B}(\mathrm{RhB})$. $\mathrm{Rh} \mathrm{B}$ was chosen because it is an organic colorant that is widely used, despite the fact that it is not environmentally friendly [18]. An amount of $0.06 \mathrm{~g}$ of $\mathrm{Bi}_{2} \mathrm{O}_{3}$ photocatalytic powder was used to degrade $40 \mathrm{ml}$ or $\mathrm{Rh} \mathrm{B}$. Degradation test has shown the success of reducing Rh B concentration as depicted in Figure 4. 


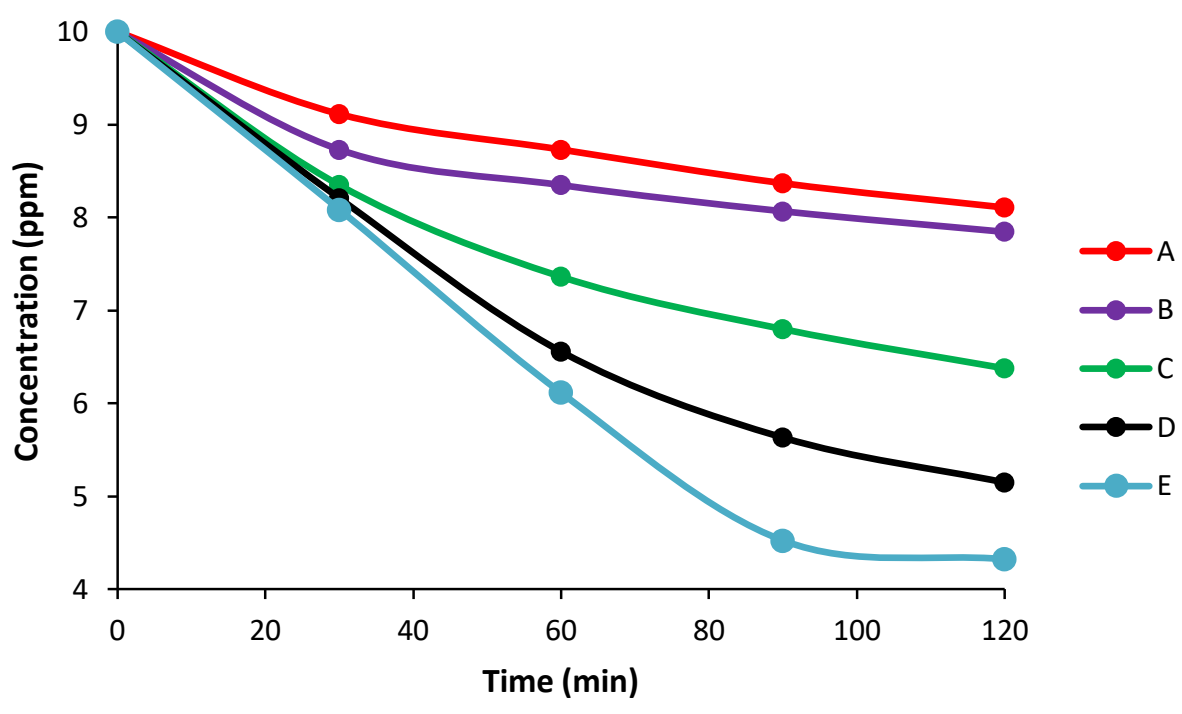

Figure 4. Lowering Rh B concentration every 10 minutes.

Results of degradation test show that sintering duration affects photocatalytic activity of $\mathrm{Bi}_{2} \mathrm{O}_{3}$, in which longer sintering period results in better photocatalytic activity. Therefore, final $\mathrm{Rh} \mathrm{B}$ concentration with degradation using sample A is greatest, followed by those using samples B, C, D, and E. Figure 5. Figure 5 shows that sample E processes the highest photocatalytic activity of $56.74 \%$, followed by samples D, C, B, and A, with photocatalytic activities of 48.49\%, 36.22\%, 21.53\%, and 18.91\%, respectively. In the meantime, Figure 6 reveals that sample $\mathrm{E}$ is capable of degrading $\mathrm{Rn} B$ the fastest, at a rate of $0.007 \mathrm{ppm} / \mathrm{min}$, followed by samples $\mathrm{D}, \mathrm{C}, \mathrm{B}$, and A, with degradation rates of $0.005 \mathrm{ppm} / \mathrm{min}, 0.003 \mathrm{ppm} / \mathrm{min}, 0.001 \mathrm{ppm} / \mathrm{min}$ and $0.001 \mathrm{ppm} / \mathrm{min}$, respectively. This means that increasing sintering temperatures has successfully improved photocatalytic activity of $\mathrm{Bi}_{2} \mathrm{O}_{3}$. Improved photocatalytic activity relates to better crystallinity, as proven by XRD test results depicted in Figure 2. Hence, it can be concluded that crystallinity affects photocatalytic activity of $\mathrm{Bi}_{2} \mathrm{O}_{3}$. Meanwhile, morphology and crystallite size do not significantly affect photocatalytic activity.

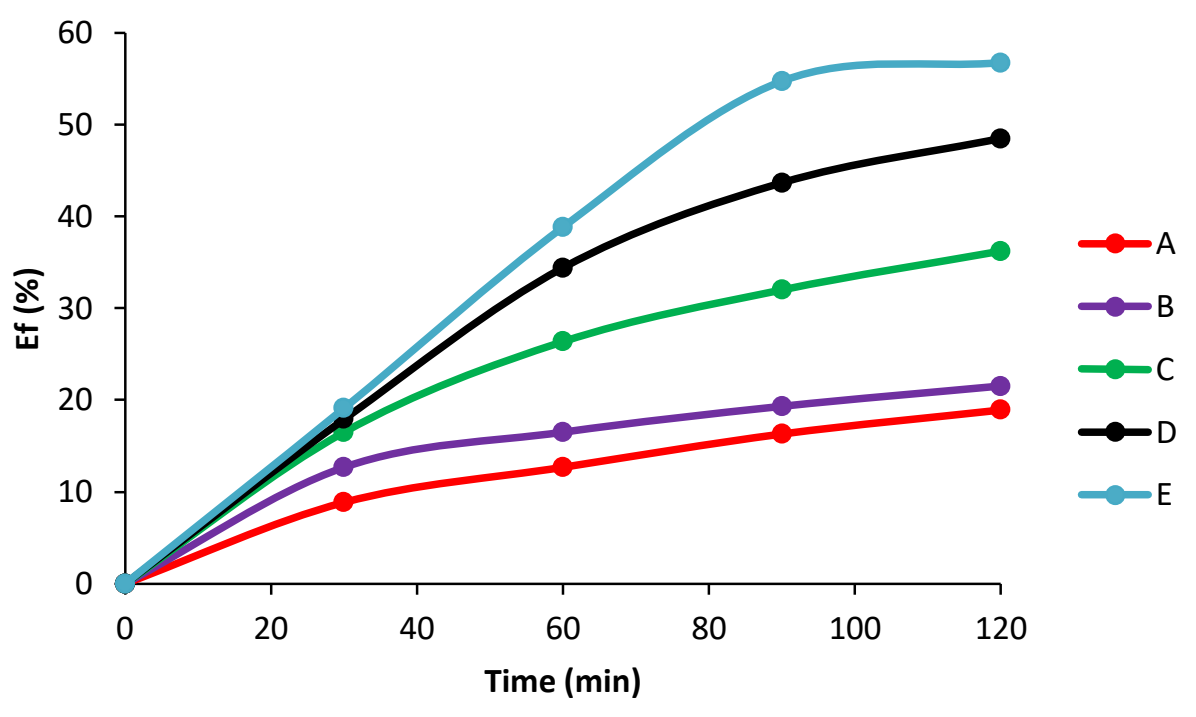

Figure 5. Photocatalytic effectiveness of $\mathrm{Bi}_{2} \mathrm{O}_{3}$ with varied sintering duration

\section{Conclusion}

This research found that different sintering temperatures affect crystallinity, morphology, and photocatalytic activity of $\mathrm{Bi}_{2} \mathrm{O}_{3}$. Crystallite size of $\mathrm{Bi}_{2} \mathrm{O}_{3}$ is optimum at sintering temperature of $500^{\circ} \mathrm{C}$; with raising sintering temperature from $400^{\circ} \mathrm{C}$ to $500^{\circ} \mathrm{C}$ increases crystallite size. Raising sintering temperature from $500^{\circ} \mathrm{C}$ to $600^{\circ} \mathrm{C}$ decreases crystallite size. Therefore, the optimum crystallite size is reached at a temperature of $500^{\circ} \mathrm{C}$. Raising sintering temperature from $400^{\circ} \mathrm{C}$ to $500^{\circ} \mathrm{C}$ increases crystallite size, and decreases band gap energy. In 
the meantime, raising sintering temperature from $500^{\circ} \mathrm{C}$ to $600^{\circ} \mathrm{C}$ results in agglomeration. Results of degradation test found that photocatalytic activity is in line with sintering temperature. This means that higher sintering temperature results in higher photocatalytic activity.

\section{Acknowledgements}

Authors would like to acknowledge all member of Smart Materials Research Center (SMARC) Diponegoro University for supporting this research.

\section{References}

[1] Chia, W-K., Yang, C-F., Chen, Y-C., The effect of $\mathrm{Bi}_{2} \mathrm{O}_{3}$ compensation during thermal treatment on the crystalline and electrical characteristics of bismuth titanate thin films, International Volume, March 2008, Pages 379-384.

[2] Zhu, B.L., Zhao, X.Z., Study on structure and optical properties of $\mathrm{Bi}_{2} \mathrm{O}_{3}$ thin films prepared by reactive pulsed laser deposition, Materials Volume, November 2006, Pages 192-198.

[3] Kalnaowakul, Phairatana, T., Ubolchollakhet, K., Sangchay, W., Rodchanarowan, A., Synthesis of Bi2O3-doped and TiO2-doped porous Lava for photocatalytic studies, Materials Today: Proceedings 5 (2018) 9312-9318.

[4] Wang, L., Zhang, J., Li, C., Zhu, H., Wenwen, Wang, W., Wang, T., Synthesis, Characterization and Photocatalytic Activity of $\mathrm{TiO}_{2}$ Film/ $\mathrm{Bi}_{2} \mathrm{O}_{3}$ Microgrid Heterojunction, Technology Volume, January 2011, Pages 59-63.

[5] Lim, H., Rawal, S.B., Integrated $\mathrm{Bi}_{2} \mathrm{O}_{3}$ nanostructure modified with $\mathrm{Au}$ nanoparticles for enhanced photocatalytic activity under visible light irradiation, Science: International Volume, June 2017, Pages 289-296.

[6] Hao, Q., Wang, R., Lu, H., Xie, C., Ao, W., Chen, D., Ma, C., Yao, W., Zhu, Y., One-pot synthesis of C/Bi/Bi2O3 composite with enhanced photocatalytic activity, Applied Catalysis B: Environmental 219 (2017) 63-72.

[7] Sutanto, H., Hidayanto, E., Mukholit, Wibowo, S., Nurhasanah, I., Hadiyanto, The Physical and Photocatalytic Properties of N-doped $\mathrm{TiO}_{2}$ Polycrystalline Synthesized by a Single Step Sonochemical Method at Room Temperature, Materials Science Forum, Vol. 890, pp 121-126.

[8] D’Angelo, D., Fillice, Scarangella A, Iannazzo, Comagnini, Scallese, $\mathrm{Bi}_{2} \mathrm{O}_{3} / \mathrm{Nexar}^{\circledR}$ polymer nanocomposite membranes for azo dyes removal by UV-vis or visible light irradiation, Today Available online 15 December 2017.

[9] Zhang, L., Hoshimoto, Y., Taishi, T., Nakamura, I., Ni, Q., Fabrication of flower-shaped $\mathrm{Bi}_{2} \mathrm{O}_{3}$ superstructure by a facile template-free process,

[10] Guishui, L., Lijun, C., Bing, Z., Yi, L., 2016, Novel $\mathrm{Bi}_{2} \mathrm{O}_{3}$ loaded sepiolite photocatalyst: Preparation and characterization, Materials Letters 168 (2016) 143-145.

[11] Matysiak, W., Tański, T., Jarka, P., Nowak, M., Kępińska, M., Szperlich, P., Comparison of optical properties of $\mathrm{PAN} / \mathrm{TiO}_{2}, \mathrm{PAN} / \mathrm{Bi}_{2} \mathrm{O}_{3}$, and PAN/SbSI nanofibers, Materials Volume, September 2018, Pages 145-151.

[12] Patil, S. P., Bethi, B., Sonawane, G. H., Shrivasta, V. S., Sonawane, S., 2015, Efficient adsorption and photocatalytic degradation of Rhodamine Bdye over Bi2O3-bentonite nanocomposites: A kinetic study, Journal of Industrial and Engineering Chemistry 34 (2016) 356-363.

[13] Gao., N., Lu, Z., Zhao, X., Zhu, Z., Wang, Y., Wang, D., Hua, Z., Li, C., Huo, P., Song, M., 2016, Enhanced photocatalytic activity of a double conductive C/Fe3O4/Bi2O3 composite photocatalyst based on biomass, Chemical Engineering Journal 304 (2016) 351-361.

[14] Guan, Z., Wang, H., Wang, X., Hu, J., Du, R., 2018, Title: Fabrication of heterostructured $\beta$-Bi2O3-TiO2 nanotube array composite film for photoelectrochemical cathodic protection applications, Corrosion Science https://doi.org/10.1016/j.corsci.2018.02.048.

[15] Chen, D., Wu, S., Fang, J., Lu, S., Zhou, G. Y., Feng, W., Yang, F., Chen, Y., Fang, Z. Q., 2018, A nanosheet-like $\alpha$-Bi2O3/g-C3N4 heterostructure modified by plasmonic metallic $\mathrm{Bi}$ and oxygen vacancies with high photodegradation activity of organic pollutants, Separation and Purification Technology 193 (2018) 232-241.

[16] B. Ohtani, Y. Ogawa, S. Nishimoto, J. Phys. Chem. B 5647 (1997) 3746-3752.

[17] N. Mahdjoub, N. Allen, P. Kelly, V. Vishnyakov, J. Photochem. Photobiol. A: Chem.211 (2010) 59-64. 
[18] Peng, F., Ni, Y., Zhou, Q., Kou, J., Lu, C., Xu., Z., New g-C3N4, based photocatalytic cement with enhanced visible-light photolytic activity by constructing muscovite sheet/SnO2 structure, Constructing and Building Materials, Volume 179.10 August 2018, pages 315-325. 